\title{
Genelleştirilmiş Trapezoidal Bulanık Esnek Kümeler: Yeşil Tedarikçi Seçimi Problemine Uygulanması
}

\author{
Generalized Trapezoidal Fuzzy Soft Set: Application to Green Supplier Selection \\ Problem
}

\author{
Dr. Öğr. Üyesi Nalan Gülten AKIN (iD) 1
}

\begin{abstract}
$\ddot{O} z$
Üretim faaliyetlerinin aksamaması, ürün ya da hizmet kalitesinin geliştirilebilmesi ve ürünlerin toplam maliyetlerinin kontrol altında tutulabilmesi için tedarikçilerin değerlendirilmesi ve seçimi organizasyonlar açısından stratejik kararlar arasında yer almaktadır. Son yıllarda çevrenin korunmasına yönelik olarak yapılan yasal düzenlemeler artmış ve müşteriler çevre konusunda daha bilinçli hale gelmiştir. Bu nedenle ürünlerin çevreye olan zararlı etkilerini azaltmak için ürünlerin üretiminde kullanılan hammaddenin temininden, ürünün müşteriye teslim edilmesine kadar geçen tüm süreçlerde organizasyonlar faaliyetlerinin tamamını çevreye duyarlı hale getirmek zorundadır. Tedarikçi seçimi ise bu faaliyetlerin başlangıç noktasını oluşturmaktadır. Tedarikçi seçimi probleminde alternatiflerin değerlendirilebilmesi ve seçimi için kalitatif ve kantitatif çok sayıda kriter dikkate alınmaktadır. Kalitatif kriterlere göre alternatiflerin değerlendirilmesi genellikle dilsel ifadeler kullanılarak yapılmaktadır ve bulanık sayılara dönüştürülmektedir. Bu nedenle bu problemlerin çözümünde genellikle bulanık ya da bulanık olmayan çok kriterli karar verme yöntemleri kullanılmaktadır. Genelleştirilmiş trapezoidal bulanık esnek kümeler özellikle bulanık ortamda karar vermeyi kolaylaştıran tekniklerdir. Trapezoidal bulanık esnek kümeler ile kesin olmayan ya da belirsiz bilgiler etkili bir şekilde dilsel değişkenler olarak tanımlanabilmektedir ve bu nedenle çok kriterli karar verme yöntemlerine alternatif olarak kullanılabileceği düşünülmektedir. Bu amaçla çalışmada, genelleştirilmiş trapezoidal bulanık esnek küme yaklaşımı yeşil tedarikçi seçimi problemine uygulanarak, elde edilen sonuçlar analiz edilmiştir. Çalışmanın sonucunda genelleştirilmiş trapezoidal bulanık esnek kümelerin çok kriterli karar verme yaklaşımlarının yerine kullanılabileceği görülmüştür.
\end{abstract}

Anahtar Kelimeler: Bulanık esnek küme, genelleştirilmiş trapezoidal bulanık esnek küme, yeşil tedarikçi seçimi

Makale Türü: Araştırma

\begin{abstract}
Evaluation and selection of suppliers are among the strategic decisions for organizations in order to not to interrupt production activities, improve product or service quality and keep the total cost of products under control. In recent years, the legal regulations for environmental protection have increased and customers have become more conscious about the environment. Therefore, in order to reduce the harmful effects of the products to the environment, organizations must make all their activities sensitive to the environment in all the processes from the procurement of the raw materials used in the production of the products to distribution of products to customers. Supplier selection is the starting point of these activities. Numerous qualitative and quantitative criteria are considered for the selection and evaluation of alternatives in the supplier selection problem. Evaluation of alternatives according to qualitative criteria is usually done using linguistic expressions and converted to fuzzy numbers. Therefore, fuzzy or non-fuzzy multi-criteria decision making methods are generally used to solve these problems. Generalized trapezoidal fuzzy soft set are techniques that facilitate decision making, especially in fuzzy environments. With trapezoidal fuzzy
\end{abstract}

${ }^{1}$ Yozgat Bozok Üniversitesi, İktisadi ve İdari Bilimler Fakültesi, nalan.akin@ bozok.edu.tr.

Atıf için (to cite): Akın, N.G. (2021). Genelleştirilmiş trapezoidal bulanık esnek kümeler: yeşil tedarikçi seçimi problemine uygulanmas1. Afyon Kocatepe Üniversitesi Sosyal Bilimler Dergisi, 23(1), 158-171. 
soft sets, uncertain or ambiguous information can be effectively defined as linguistic variables and is therefore considered to be an alternative to multi-criteria decision-making. In this study, generalized trapezoidal fuzzy flexible cluster approach was applied to green supplier selection problem and the results were analyzed. As a result of the study, it is seen that generalized trapezoidal fuzzy flexible clusters can be used instead of multi criteria decision making approaches.

Keywords: Fuzzy soft set, generalized trapezoidal fuzzy soft set, green supplier selection

Paper Type: Research

\section{Giriş}

Günümüz pazarlarındaki yoğun rekabet ortamı organizasyonları maliyetlerini azaltmaları, esnekliklerini, kalite ve hizmet düzeylerini artırmaları için zorlamaktadır. Tedarik zinciri yönetimi örgütsel hedeflere ulaşmak için üretimde kullanılacak malzemelerin tedarik edilmesi, ürünlerin hazırlanması, lojistik kanallar aracılığı ile dağıtımının yapılması ve ürünlerin müşterilere ulaştırılması gibi birbiriyle ilişkili faaliyetlerin koordinasyonu ve yönetilmesidir (Hervani, Helms ve Sarkis, 2005, s.331). Tedarik zinciri yönetimi bakış açısı ile ürün ya da hizmet kalitesinin geliştirilebilmesi ve ürünlerin toplam maliyetlerinin kontrol altında tutulabilmesi için tedarikçilerin değerlendirilmesi ve seçimi organizasyonların genel hedefleri arasındaki stratejik uygulamalar arasında yer almaktadır. Tedarikçi seçiminde kalitatif ve kantitatif çok sayıda kriterin dikkate alınması sebebiyle bu problemler çok kriterli karar verme problemleri olarak tanımlanmaktadır (Yazdani, 2014, s. 443-444; Kannan vd., 2013, s. 356).

Son yıllarda çevre bilincinin ve çevrenin korunmasına yönelik uygulamaların artması sebebiyle organizasyonlar da bu konuda daha fazla duyarlı olmaya başlamışlardır (Yazdani, 2014, s.444). Çevrenin korunmasına yönelik yapılan yasal düzenlemeler, müşterilerin çevre konusunda daha bilinçli hale gelmeleri ve daha çok yeşil ürünleri satın alma davranışları, organizasyonların ve organizasyonların içinde yer aldığı tedarik zincirlerinin çevreci uygulamalarını zorunlu hale getirmiştir. Bu uygulamaların bir parçası olan yeşil tedarikçi seçimi, geleneksel tedarikçi seçimi yaklaşımları ile bütünleştirilerek, tedarikçilerin değerlendirilmesinde ve seçiminde fiyat, kalite, esneklik, hız, kapasite, hizmet düzeyi gibi faktörlerle birlikte karbon emisyonu, karbon ayak izi, enerji tüketimi ve verimliliği, su tüketimi, katı, sıvı ya da gaz atıkların düzeyi, geri dönüşüm girişimleri gibi faktörlerin de kullanılmasına yol açmıştır (Awasthi ve Kannan, 2016, s.104; Lu, Wu ve Kuo, 2007, s.4325; Banaeian vd. 2018, s.337).

Bulanık küme teorisi ilk defa 1965 yılında Zadeh tarafindan yapılan Fuzzy Sets adlı çalışma ile tanıtılmıştır (Zadeh, 1965). Bulanık teori, genellikle dilsel terimlerle ifade edilen kesin olmayan ve belirsiz bilgilerin olması durumunda karar verme yetenekleri sağlamak için geliştirilmiştir (Bansal, Biswas ve Singh, 2017, s.125). Buna göre bir bulanık $\tilde{A}$ kümesi $[0,1]$ aralığında tanımlanır ve üyelik fonksiyonu $\mu_{\tilde{A}}: \mathrm{E} \rightarrow[0,1]$ olarak gösterilir. Bir bulanık küme içindeki tüm bilgiler üyelik fonksiyonu tarafından temsil edilir (Baskaya ve Öztürk, 2011, s.8283). Bu çalışmada trapezoidal üyelik fonksiyonu kullanılarak hesaplamalar yapılmıştır.

$(\tilde{n})$ olarak ifade edilen bir pozitif bulanık trapezoidal say1, $\left(n_{1}, n_{2}, n_{3}, n_{4}\right)$ olarak tanımlanır. $\tilde{n}$ 'in üyelik fonksiyonu $\mu_{\tilde{n}}(x)$ ise aşağıdaki şekilde tanımlanır ve gösterilir (ChenTung, Lin ve Huang, 2006, s. 292):

$$
\mu_{\tilde{n}}(x)=\left\{\begin{array}{cl}
0, & x<n_{1} \\
\frac{x-n_{1}}{n_{2}-n_{1}}, & n_{1} \leq x \leq n_{2} \\
1, & n_{2} \leq x \leq n_{3} \\
\frac{x-n_{4}}{n_{3}-n_{4}}, & n_{3} \leq x \leq n_{4} \\
0, & x>n_{4} .
\end{array}\right.
$$




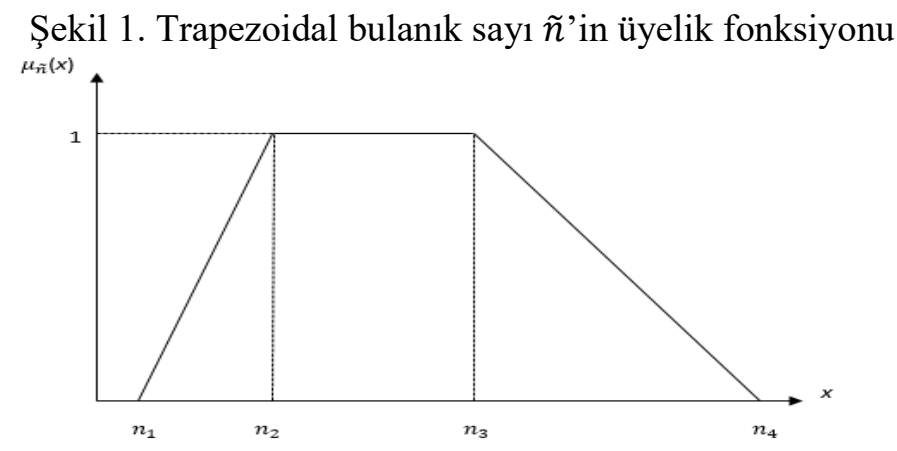

Kaynak: Xiao, Xia, Gong ve Li, 2012, s.5846.

Bulanık küme teorisi, olasılık teorisi, aralık aritmetiği gibi matematiksel yöntemlerin, çeşitli belirsizlikler içeren problemlerin çözümü için kendi içinde bazı zorluklara sahip olması nedeniyle, Molodtsov tarafından 1999 yılında yapılan çalışmada bu tür problemlerin çözümüne yeni bir bakış açısı getiren esnek küme teorisi tanımlanmıştır. Esnek küme teorisinde reel değerli fonksiyon yerine seçim fonksiyonu kullanılarak, belirsizlik ortadan kaldırılmıştır (Molodtsov, 1999, s.19; Maji, Roy ve Biswas, 2002, s.1077). Bulanık esnek küme kavramı ilk defa 2001 yılında Maji, Biswas ve Roy tarafından yapılan çalışmada (Çelik, 2016, s.121); genelleştirilmiş bulanık esnek küme kavramı ise ilk defa Majumdar ve Samanta (2010) tarafindan yapılan çalışmada tanımlanmıştır (Majumdar ve Samanta, 2010). Xiao, Xia, Gong ve Li (2012) tarafindan yapılan çalışmada, esnek kümeler ile trapezoidal bulanık sayılar bütünleştirilerek, trapezoidal bulanık esnek kümeler tanımlanmıştır. Söz konusu çalışmada yöntem çok kriterli karar verme problemine uygulandığında, trapezoidal bulanık esnek kümelerin kesin olmayan ya da belirsiz bilgilerin etkili bir şekilde dilsel değişkenler olarak tanımlanabileceği gösterilmiştir (Xiao, Xia, Gong ve Li, 2012, s. 5851). Ancak trapezoidal bulanık esnek kümeler için parametrelerin öz niteliğinin belirsiz ve karmaşık olması modelin dezavantajıdır. Çelik (2016) ise, kendisi de trapezoidal bulanık olan bir genelleştirilmiş parametreyi tanıtarak, genelleştirilmiş trapezoidal bulanık esnek küme kavramını tanımlamış ve bu yapıya ait bazı özellikleri incelemiştir. Xiao vd. tarafından geliştirilen yöntemle kıyaslandığında genelleştirilmiş trapezoidal bulanık esnek kümelerin niteliksel belirsizliği daha fazla anlaşılır hale getirdiği sonucuna ulaşmıştır (Çelik, 2016, s.123).

Çok kriterli karar verme problemleri, kriterler ve kriterlere verilen ağırlıklar ile her bir alternatifin derecelendirilmesi ile karakterize edilir. Klasik çok kriterli karar verme yöntemleri alternatiflerin derecelerinin ve kriterlerin ağırlıklarının net sayılarla ifade edildiği varsayımına dayanmaktadır. Net sayılar tek bir noktada tanımlıdır ve üyelik derecesi 0 ya 1'dir. Ancak gerçek hayat problemlerinde belirsizlikler vardır. Bir başka ifade ile sadece siyah ve beyaz değil, gri de vardır. Dolayısıyla bulanık bir sayı belirli bir aralıkta tanımlandığı için 0 ile 1 arasında herhangi bir değer alabilir. Çok kriterli karar verme problemlerinin çözümünde belirsizlik faktörlerini ifade eden, doğrusal üyelik fonksiyonları, parçalı doğrusal üyelik fonksiyonları, üstel üyelik fonksiyonları, hiperbolik üyelik fonksiyonları, S-eğrisi üyelik fonksiyonları gibi çeşitli üyelik fonksiyonları uygulanır. Bir trapezoidal bulanık sayının üyelik fonksiyonu, dilsel değerlendirmelerin neden olduğu belirsiz ifadelerin objektif olarak sayısal değerlere dönüştürülebildiği parçalı doğrusal ve tripezoidal bir fonksiyondur (Xiao, Xia, Gong ve Li, 2012, s.5844-5845).

$\mathrm{Bu}$ çalışma, genelleştirilmiş trapezoidal bulanık esnek küme yaklaşımının özellikle bulanık ortamda kullanılan çok kriterli karar verme tekniklerine alternatif oluşturabileceği düşüncesinden hareketle hazırlanmıştır. $\mathrm{Bu}$ amaçla genelleştirilmiş trapezoidal bulanık esnek küme yaklaşımı yeşil tedarikçi seçimi problemine uygulanarak, elde edilen sonuçlar analiz edilmiştir. Literatürde trapezoidal bulanık esnek küme yaklaşımı kullanılarak hazırlanmış çalışma sayısı oldukça sınırlıdır ve yeşil tedarikçi seçimi problemi özelinde ise herhangi bir uygulamaya 
rastlanmamıştır. Benzer nitelikteki çalışmalar için de kolaylıkla uygulanabilir bir yöntem olması sebebiyle çalışmanın literatüre katkı sağlayacağı düşünülmektedir. Çalışma, giriş, literatür taramas1, metodoloji, uygulama ve sonuç olmak üzere beş bölümden oluşmaktadır.

\section{Literatür Taraması}

$\mathrm{Bu}$ kısımda öncelikle literatür taraması sonucunda ulaşılan bulanık esnek kümeler yaklaşımının yer aldığı çalışmalara ve sonrasında yeşil tedarikçi seçimi ile ilgili olarak yapılan çalışmalara ilişkin bilgiler verilmiştir.

Roy ve Maji (2007), karar verme problemlerinde bulanık esnek kümeler yaklaşımını uygulayarak, bir algoritma geliştirmişler ve örnek bir problem üzerinde elde etmiş oldukları sonuçları sunmuşlardır. Yao, Liu ve Yan (2008) bulanık esnek küme ve esnek bulanık küme arasındaki ilişkiyi analiz etmişlerdir. Kong, Gao ve Wang (2009) ise, Roy ve Maji (2007) tarafından geliştirilen bulanık esnek algoritmanın, tüm karar verme problemleri için genelleştirilemeyeceğini örnek bir problemi çözerek göstermişlerdir. Ahmad ve Kharal (2009) bulanık esnek birleşimin ve bulanık esnek kesişimin özelliklerini örnekler üzerinde inceleyerek, keyfi bulanık esnek birleşim ve kesişimi tanımlamışlardır. Ayrıca bulanık esnek küme teorisinde DeMorgan yasasının uygulamasını göstermişlerdir. Guneri, Yucel ve Ayyildiz (2009) bir tekstil firmasında tedarikçi seçim problemi için bulanık küme teorisi ile doğrusal programlama yaklaşımını bütünleşik olarak uygulamışlardır. Çalışmada tedarikçi seçim kriterlerinin ağırlıklarının ve derecelerinin belirlenebilmesi için kullanılan dilsel ifadeler trapezoidal bulanık sayılarla ifade edilmiştir. Majumdar ve Samanta (2010) genelleştirilmiş bulanık esnek kümeleri tanımlayarak, yöntemi karar verme problemlerinin çözümü ve ayrıca tıp tanısı için uygulamışlardır. Çağman, Enginoğlu ve Çıtak (2011) bütünleşik bulanık kümeler üzerinde çalışarak, uygulama adımlarını personel seçimi problemi örneği üzerinde açıklamışlardır. Borah, Neog ve Sut (2012) yaptıkları çalışmada bulanık esnek kümeler ile ilgili literatürü gözden geçirerek, yeni birtakım önermeler sunmuşlar ve bu önermelere ilişkin ispatları göstermişlerdir. Aktaş ve Bulut (2013), genelleştirilmiş bulanık esnek kümeler üzerinde genelleştirilmiş bulanık esnek grup ve genelleştirilmiş bulanık esnek halka tanımları yaparak, bu kavramlara ilişkin temel bazı özellikleri açıklamışlardır. Xie, Wen ve Li (2014) tıp tanısı probleminin çözümü için gri ilişkisel analiz ve D-S teorisine dayalı karar vermede bulanık esnek kümeleri uygulamışlardır. Çelik (2016) tarafından yapılan çalışmada genelleştirilmiş trapezoidal bulanık esnek kümelerin karar verme problemlerindeki uygulanabilirliğini değerlendirmek üzere tıp tanısı için örnek bir çalışma sunulmuştur. Taş, Yılmaz Özgür ve Demir (2017) esnek ve bulanık esnek kümeleri kullanarak, stokların etkili yönetimi ve takibi probleminin çözümü ile ilgili bir uygulama yapmışlardır.

Lu, Wu ve Kuo (2007) yeşil tedarikçi seçiminde AHP (Analitik Hiyerarşi Prosesi) yöntemini uygulamıştır. Kuo, Wang ve Tien (2010) yeşil tedarikçi seçimi probleminde yapay sinir ağları ile çok özellikli karar analiz yöntemlerinden veri zarflama analizi ve analitik ağ süreci yaklaşımını bütünleştirerek, karma yöntemler uygulamışlardır. Kannan, Khodaverdi, Olfat, Jafarian ve Diabat (2013) karar kriterlerinin önem düzeyini ve en iyi yeşil tedarikçiyi belirlemek için bulanık AHP ve bulanık TOPSIS yöntemlerini, işletmenin kalite, kapasite, maliyet gibi kısıtlarla ilgili hedefleri için ise çok amaçlı doğrusal programlama modelini bütünleştirerek, yeşil tedarikçi seçiminde yeni bir yaklaşım önerisinde bulunmuşlardır. Yazdani (2014) yeşil tedarikçi seçimi probleminde karar kriterlerinin ağırlıklarının belirlenmesi için çok kriterli karar verme tekniklerinden AHP; tedarikçilerin tercih sıralamalarını yapabilmek için de bulanık TOPSIS yöntemini kullanmıştır. Govindan, Rajendran, Sakis ve Murugesan (2015) 1997 ve 2011 yılları arasında yapılan, yeşil tedarikçilerin değerlendirilmesi ve seçiminde kullanılan çok kriterli karar verme tekniklerinin uygulandığı çalışmalara ilişkin bir literatür araştırması yapmışlardır. Çalışma sonucunda en fazla tercih edilen yöntemin AHP olduğu belirlenmiştir. Freeman ve Chen (2015) AHP- Entropi ve TOPSIS yöntemlerini kullanarak yeşil tedarikçi problemini çözmüşlerdir. Awasthi ve Kannan (2016) bulanık ortamda nominal grup tekniği ile yeşil tedarikçi geliştirme programını değerlendirebilmek için gerekli olan kriterleri tanımlamışlardır. Ayrıca bulanık 
VIKOR yöntemi ile en iyi program sıralamasını yapmışlardır. Belirlenen parametrelerin sıralama üzerindeki etkilerini ise duyarlılık analizi ile karşılaştırmışlardır. Şişman (2016) tarafından yapılan çalışmada ise, belirsizlik ortamında nominal grup tekniği ile yeşil tedarikçi geliştirme programlarını değerlendirmek üzere kriterler belirlenmiş; alternatif programların değerlendirilmesi ve sıralaması için bulanık MOORA yöntemi kullanılmıştır. Modelde yer alan kriter ağırlıklarının alternatif programlar üzerindeki etkileri ise duyarlılık analiz ile test edilmiştir.

\section{Yöntem}

Genelleştirilmiş trapezoidal bulanık esnek kümelerin uygulama adımları aşağıda detaylı olarak açıklanmıştır (Çelik, 2016, s.123-127):

Adım 1: Dilsel ifadeler kullanılarak karar vericiler tarafından karar kriterlerine göre alternatiflerin değerlendirilmesi. Bu adımda karar vericiler çok zayıf, zayıf, orta derecede zayıf, uygun, orta derecede iyi, iyi ve çok iyi dilsel ifadelerini kullanarak her bir alternatifi karar kriterleri açısından değerlendirmektedir.

Adım 2: Karar kriterlerinin dilsel ifadeler kullanılarak karar vericiler tarafından değerlendirilmesi. Adım 1'de olduğu gibi bu adımda da karar vericiler çok zayıf, zayıf, orta derecede zayıf, uygun, orta derecede iyi, iyi ve çok iyi dilsel ifadelerini kullanarak bu defa karar kriterlerini değerlendirmektedirler. Yapılan değerlendirme sonucunda kriter ağırlıkları elde edilmektedir.

Adım 3: Dilsel ifadelerin trapezoidal bulanık sayının üyelik fonksiyonu yardımıyla nümerik ifadelere dönüştürülmesi. Bu adımda birinci ve ikinci adımda dilsel ifadelere göre yapılan değerlendirmeler trapezoidal bulanık sayının üyelik fonksiyonu kullanılarak, sayısal değerlere dönüştürülür. Dilsel ifadelere karşılık gelen trapezoidal bulanık sayılar Şekil 1'de yer alan Niteliksel Değişkenler Grafiği yardımı ile belirlenir.

\section{Şekil 2. Niteliksel değişkenler grafiği}

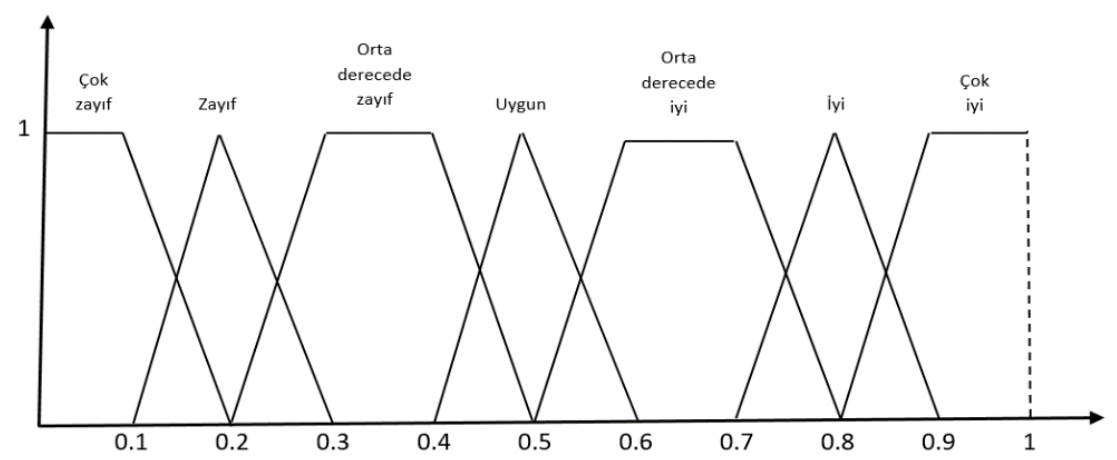

Kaynak: Xiao, Xia, Gong, ve Li, 2012, s.5847

Adım 4: Tüm karar vericiler için genelleştirilmiş trapezoidal bulanık esnek kümelerin oluşturulması. Bu adımda her bir karar verici tarafından karar kriterlerine göre alternatiflerin değerlendirilmesi sonucunda ayrı ayrı elde edilen trapezoidal bulanık sayılar birleştirilerek, tüm değerleri kapsayacak şekilde genelleştirilmiş trapezoidal bulanık esnek kümeler ve ayrıca kriter ağırlıklarına göre belirlenen genelleştirilmiş trapezoidal bulanık alt küme değerleri elde edilir.

Adım 5: Durulaştırılmış değerler çizelgesinin hazırlanması. Bir önceki adımda elde edilen genelleştirilmiş trapezoidal bulanık esnek küme ve kriter ağırlıklarına göre belirlenen genelleştirilmiş trapezoidal bulanık alt küme $\tilde{n}=\left(n_{1}, n_{2}, n_{3}, n_{4}\right)$ olmak üzere $\tilde{n}$ trapezoidal bulanık sayısının durulaştııılmış $t$ değeri aşağıdaki eşitlik yardımı ile hesaplanır.

$$
t=\frac{n_{1}+n_{2}+n_{3}+n_{4}}{4}
$$


Adım 6: Durulaştırılmış dereceler çizelgesinin hazırlanması. Bu adımda beşinci adımda elde edilen değerler karşılaştırılarak, en yüksek durulaştırılmış değere sahip olan alternatif ya da alternatifler belirlenir.

Adım 7: Toplam puanların hesaplanması ve alternatiflerin sıralanması. Altıncı adımda belirlenen alternatiflere ait durulaştırma derecesi ile aynı sütuna ait olası derecelerin çarpımının toplamı alınarak, her bir alternatif için toplam puanlar belirlenir. Alternatiflerin sıralaması ise en yüksek puandan düşük olana doğru yapılır.

\section{Uygulama ve Bulgular}

$\mathrm{Bu}$ çalışmada, genelleştirilmiş trapezoidal bulanık esnek kümeler teorisinin karar problemlerine uygunluğunu test etmek amaçlanmıştır. Bu nedenle yöntem, Banaeian vd. (2018) tarafından yapılan yeşil tedarikçi seçimi problemine uygulanmıştır. Banaeian vd. (2018) yenilebilir sebze yağları ve deterjan üretimi yapan bir firma için üç adet karar vericinin görüşleri doğrultusunda en uygun zeytinyağı, palm yağ 1 , ayçiçek yağı ve soya yağı tedarikçilerini seçmek için bulanık TOPSIS, bulanık VIKOR ve bulanık GRA yöntemlerini karşılaştırmışlardır. Analizlerin yapılabilmesi için hizmet düzeyi, kalite, fiyat ve EMS (Environmental Management Systems- çevresel yönetim sistemleri) olmak üzere dört adet karar kriteri belirlenmiştir. Bu kriterlerden hizmet düzeyi, kalite ve fiyat tedarikçi seçiminde birincil konvansiyonel ölçütleri (geleneksel tedarikçi seçim kriterlerini), EMS ise yeşil ölçütleri göstermektedir. Ayrıca karar kriterleri açısından en uygun tedarikçinin seçilebilmesi için dört adet zeytinyağı, üç adet palm yağı ve üç adet ayçiçek yağı ve soya yağı tedarikçisi belirlenmiştir. Tedarikçilerin seçimi yağ çeşidine göre kendi içinde gerçekleştirilmiştir.

Genelleştirilmiş trapezoidal bulanık esnek kümeler teorisinin yeşil tedarikçi seçimi problemine uygulama adımları aşağıda detaylı olarak açıklanmıştır:

Adım 1: Oi zeytinyağı tedarikçilerini $(i=1,2,3,4)$, Pi palm yağı tedarikçilerini $(i=1,2,3), \mathrm{Si}$ ayçiçek yağ 1 ve soya yağ tedarikçilerini $(i=1,2,3)$ ve $C i$ karar kriterlerini $(i=1,2,3,4$ ve $\mathrm{C} 1=$ Hizmet düzeyi, C2 = Kalite, C3 = Fiyat ve C4 = EMS) göstermek üzere; karar kriterlerine göre tedarikçiler dilsel ifadeler kullanılarak karar vericiler tarafından değerlendirilmiştir. Değerlendirme sonuçları Tablo 1, Tablo 2 ve Tablo 3'te yer almaktadır:

Tablo 1. Zeytinyağı tedarikçileri

\begin{tabular}{|c|c|c|c|c|c|}
\hline \multirow{7}{*}{$\begin{array}{c}\text { KARAR } \\
\text { VERİCI } \\
1\end{array}$} & \multirow[b]{2}{*}{ TEDARİKÇİLER } & \multicolumn{4}{|c|}{ KRİTERLER } \\
\hline & & $\mathrm{C} 1$ & $\mathrm{C} 2$ & C3 & $\mathrm{C} 4$ \\
\hline & $\mathrm{O} 1$ & Uygun & Orta derecede & Orta derecede & Çok iyi \\
\hline & $\mathrm{O} 2$ & İyi & zayif & zayıf & Orta derecede iyi \\
\hline & $\mathrm{O} 3$ & Orta derecede & Uygun & Uygun & İyi \\
\hline & $\mathrm{O} 4$ & zayıf & Çok iyi & Orta derecede iyi & Orta derecede \\
\hline & & Zayif & Çok zayıf & Zayıf & zayif \\
\hline & $\mathrm{O} 1$ & Zayif & İyi & Orta derecede & Uygun \\
\hline KARAR & $\mathrm{O} 2$ & Uygun & İyi & zayıf & Uygun \\
\hline VERİCİ & $\mathrm{O} 3$ & Çok iyi & Orta derecede & Orta derecede iyi & Çok iyi \\
\hline 2 & $\mathrm{O} 4$ & Orta derecede & zayıf Orta & Çok iyi & Orta derecede iyi \\
\hline & & zayıf & derecede iyi & Uygun & \\
\hline & $\mathrm{O} 1$ & Orta derecede & Uygun & İyi & Orta derecede iyi \\
\hline KARAR & $\mathrm{O} 2$ & zayif & Zayif & İyi & İyi \\
\hline VERİCİ & $\mathrm{O} 3$ & Çok iyi & İyi & İyi & İyi \\
\hline 3 & $\mathrm{O} 4$ & Zayif & Zayif & İyi & İyi \\
\hline
\end{tabular}


Tablo 2. Palm yağı tedarikçileri

\begin{tabular}{|c|c|c|c|c|c|}
\hline \multirow{5}{*}{$\begin{array}{c}\text { KARAR } \\
\text { VERİCI } \\
1\end{array}$} & \multirow[b]{2}{*}{ TEDARİKÇİLER } & \multicolumn{4}{|c|}{ KRİTERLER } \\
\hline & & $\mathrm{C} 1$ & $\mathrm{C} 2$ & $\mathrm{C} 3$ & $\mathrm{C} 4$ \\
\hline & P1 & İyi & Orta derecede iyi & Orta derecede iyi & İyi \\
\hline & P2 & Zayif & Orta derecede & Orta derecede & Zayif \\
\hline & P3 & Orta derecede iyi & $\begin{array}{c}\text { zayif } \\
\text { Uygun }\end{array}$ & $\begin{array}{c}\text { zayif } \\
\text { Uygun }\end{array}$ & Orta derecede iyi \\
\hline KARAR & $\mathrm{P} 1$ & İyi & Orta derecede iyi & Orta derecede iyi & Orta derecede iyi \\
\hline VERİCİ & P2 & Zayif & Zayif & Zayif & Zayif \\
\hline 2 & P3 & Uygun & Uygun & İyi & Uygun \\
\hline KARAR & $\mathrm{P} 1$ & Çok iyi & Çok iyi & İyi & İyi \\
\hline VERİCI & P2 & Orta derecede iyi & Uygun & Orta derecede & Orta derecede \\
\hline 3 & P3 & Orta derecede iyi & Uygun & zayıf İyi & $\begin{array}{c}\text { zayıf Orta } \\
\text { derecede zavıf }\end{array}$ \\
\hline
\end{tabular}

Tablo3. Ayçiçek yağı ve soya yağı tedarikçileri

\begin{tabular}{|c|c|c|c|c|c|}
\hline \multirow{5}{*}{$\begin{array}{c}\text { KARAR } \\
\text { VERİCI } \\
1\end{array}$} & \multirow[b]{2}{*}{ TEDARİKÇİLER } & \multicolumn{4}{|c|}{ KRİTERLER } \\
\hline & & $\mathrm{C} 1$ & $\mathrm{C} 2$ & $\mathrm{C} 3$ & $\mathrm{C} 4$ \\
\hline & S1 & Çok iyi & Uygun & Çok iyi & Uygun \\
\hline & S2 & Orta derecede iyi & Orta derecede iyi & Orta derecede iyi & Orta derecede iyi \\
\hline & S3 & Zayıf & Çok iyi & Uygun & Uygun \\
\hline KARAR & S1 & İyi & Orta derecede & İyi & Uygun \\
\hline VERİCİ & S2 & Orta derecede & zayıf Uygun & İyi & Uygun \\
\hline 2 & S3 & $\begin{array}{l}\text { zayif } \\
\text { Zayif }\end{array}$ & $\begin{array}{c}\text { Orta derecede } \\
\text { zayif }\end{array}$ & $\begin{array}{c}\text { Orta derecede } \\
\text { zayif }\end{array}$ & Uygun \\
\hline KARAR & $\mathrm{S} 1$ & İyi & İyi & Orta derecede iyi & Orta derecede iyi \\
\hline VERİCİ & $\mathrm{S} 2$ & Orta derecede iyi & Orta derecede & Cok zayıf & Cok zayıf \\
\hline 3 & S3 & İyi & $\begin{array}{l}\text { zayıf } \\
\text { Zayıf }\end{array}$ & Orta derecede iyi & Orta derecede iyi \\
\hline
\end{tabular}

Adım 2: Karar kriterleri dilsel ifadeler kullanılarak karar vericiler tarafından değerlendirilmiştir. $\mathrm{Bu}$ adımda kriter ağırlıkları belirlenmiştir ve Tablo 4'te gösterilmiştir.

Tablo 4. Kriter ağırlıkları

\begin{tabular}{|c|c|c|c|c|}
\hline \multirow[b]{2}{*}{$\begin{array}{c}\text { KARAR } \\
\text { VERİCILER }\end{array}$} & \multicolumn{4}{|c|}{ KRİTERLER } \\
\hline & $\mathrm{C} 1$ & $\mathrm{C} 2$ & $\mathrm{C} 3$ & $\mathrm{C} 4$ \\
\hline 1 & İyi & İyi & Orta derecede iyi & Orta derecede zayıf \\
\hline 2 & Çok iyi & Orta derecede iyi & İyi & Uygun \\
\hline 3 & İyi & Çok iyi & Orta derecede iyi & Orta derecede iyi \\
\hline
\end{tabular}

Adım 3: Bu adımda dilsel ifadeler trapezoidal bulanık sayının üyelik fonksiyonu yardımıyla nümerik ifadelere dönüştürülmüştür. 
Tablo 5. Zeytinyağı tedarikçileri

\begin{tabular}{|c|c|c|c|c|c|}
\hline & & & KRI' & RLER & \\
\hline & TEDARİKÇİLER & $\mathrm{C} 1$ & $\mathrm{C} 2$ & C3 & $\mathrm{C} 4$ \\
\hline & $\mathrm{O} 1$ & $(0,4 ; 0,5 ; 0,5 ; 0,6)$ & $(0,2 ; 0,3 ; 0,4 ; 0,5)$ & $(0,2 ; 0,3 ; 0,4 ; 0,5)$ & $(0,8 ; 0,9 ; 1,0 ; 1,0)$ \\
\hline KARAR & $\mathrm{O} 2$ & $(0,7 ; 0,8 ; 0,8 ; 0,9)$ & $(0,4 ; 0,5 ; 0,5 ; 0,6)$ & $(0,4 ; 0,5 ; 0,5 ; 0,6)$ & $(0,5 ; 0,6 ; 0,7 ; 0,8)$ \\
\hline VERİCİ & $\mathrm{O} 3$ & $(0,2 ; 0,3 ; 0,4 ; 0,5)$ & $(0,8 ; 0,9 ; 1,0 ; 1,0)$ & $(0,5 ; 0,6 ; 0,7 ; 0,8)$ & $(0,7 ; 0,8 ; 0,8 ; 0,9)$ \\
\hline 1 & $\mathrm{O} 4$ & $(0,1 ; 0,2 ; 0,2 ; 0,3)$ & $(0,0 ; 0,0 ; 0,1 ; 0,2)$ & $(0,1 ; 0,2 ; 0,2 ; 0,3)$ & $(0,2 ; 0,3 ; 0,4 ; 0,5)$ \\
\hline & $\mathrm{O} 1$ & $(0,1 ; 0,2 ; 0,2 ; 0,3)$ & $(0,7 ; 0,8 ; 0,8 ; 0,9)$ & $(0,2 ; 0,3 ; 0,4 ; 0,5)$ & $(0,4 ; 0,5 ; 0,5 ; 0,6)$ \\
\hline KARAR & $\mathrm{O} 2$ & $(0,4 ; 0,5 ; 0,5 ; 0,6)$ & $(0,7 ; 0,8 ; 0,8 ; 0,9)$ & $(0,5 ; 0,6 ; 0,7 ; 0,8)$ & $(0,4 ; 0,5 ; 0,5 ; 0,6)$ \\
\hline VERİCİ & $\mathrm{O} 3$ & $(0,8 ; 0,9 ; 1,0 ; 1,0)$ & $(0,2 ; 0,3 ; 0,4 ; 0,5)$ & $(0,8 ; 0,9 ; 1,0 ; 1,0)$ & $(0,8 ; 0,9 ; 1,0 ; 1,0)$ \\
\hline 2 & $\mathrm{O} 4$ & $(0,2 ; 0,3 ; 0,4 ; 0,5)$ & $(0,5 ; 0,6 ; 0,7 ; 0,8)$ & $(0,4 ; 0,5 ; 0,5 ; 0,6)$ & $(0,5 ; 0,6 ; 0,7 ; 0,8)$ \\
\hline & $\mathrm{O} 1$ & $(0,2 ; 0,3 ; 0,4 ; 0,5)$ & $(0,4 ; 0,5 ; 0,5 ; 0,6)$ & $(0,7 ; 0,8 ; 0,8 ; 0,9)$ & $(0,5 ; 0,6 ; 0,7 ; 0,8)$ \\
\hline KARAR & $\mathrm{O} 2$ & $(0,8 ; 0,9 ; 1,0 ; 1,0)$ & $(0,1 ; 0,2 ; 0,2 ; 0,3)$ & $(0,7 ; 0,8 ; 0,8 ; 0,9)$ & $(0,7 ; 0,8 ; 0,8 ; 0,9)$ \\
\hline VERİCI & $\mathrm{O} 3$ & $(0,1 ; 0,2 ; 0,2 ; 0,3)$ & $(0,7 ; 0,8 ; 0,8 ; 0,9)$ & $(0,7 ; 0,8 ; 0,8 ; 0,9)$ & $(0,7 ; 0,8 ; 0,8 ; 0,9)$ \\
\hline 3 & O4 & $(0,4 ; 0,5 ; 0,5 ; 0,6)$ & $(0,1 ; 0,2 ; 0,2 ; 0,3)$ & $(0,7 ; 0,8 ; 0,8 ; 0,9)$ & $(0,7 ; 0,8 ; 0,8 ; 0,9)$ \\
\hline
\end{tabular}

Tablo 6. Palm yağı tedarikçileri

\begin{tabular}{|c|c|c|c|c|c|}
\hline \multirow{5}{*}{$\begin{array}{c}\text { KARAR } \\
\text { VERİCI } \\
1\end{array}$} & \multirow[b]{2}{*}{ TEDARİKÇİLER } & \multicolumn{4}{|c|}{ KRİTERLER } \\
\hline & & $\mathrm{C} 1$ & $\mathrm{C} 2$ & $\mathrm{C} 3$ & $\mathrm{C} 4$ \\
\hline & P1 & $(0,7 ; 0,8 ; 0,8 ; 0,9)$ & $(0,5 ; 0,6 ; 0,7 ; 0,8)$ & $(0,5 ; 0,6 ; 0,7 ; 0,8)$ & $(0,7 ; 0,8 ; 0,8 ; 0,9)$ \\
\hline & P2 & $(0,1 ; 0,2 ; 0,2 ; 0,3)$ & $(0,2 ; 0,3 ; 0,4 ; 0,5)$ & $(0,2 ; 0,3 ; 0,4 ; 0,5)$ & $(0,1 ; 0,2 ; 0,2 ; 0,3)$ \\
\hline & P3 & $(0,5 ; 0,6 ; 0,7 ; 0,8)$ & $(0,4 ; 0,5 ; 0,5 ; 0,6)$ & $(0,4 ; 0,5 ; 0,5 ; 0,6)$ & $(0,5 ; 0,6 ; 0,7 ; 0,8)$ \\
\hline KARAR & P1 & $(0,7 ; 0,8 ; 0,8 ; 0,9)$ & $(0,5 ; 0,6 ; 0,7 ; 0,8)$ & $(0,5 ; 0,6 ; 0,7 ; 0,8)$ & $(0,5 ; 0,6 ; 0,7 ; 0,8)$ \\
\hline VERİCİ & $\mathrm{P} 2$ & $(0,1 ; 0,2 ; 0,2 ; 0,3)$ & $(0,1 ; 0,2 ; 0,2 ; 0,3)$ & $(0,1 ; 0,2 ; 0,2 ; 0,3)$ & $(0,1 ; 0,2 ; 0,2 ; 0,3)$ \\
\hline 2 & P3 & $(0,4 ; 0,5 ; 0,5 ; 0,6)$ & $(0,4 ; 0,5 ; 0,5 ; 0,6)$ & $(0,7 ; 0,8 ; 0,8 ; 0,9)$ & $(0,4 ; 0,5 ; 0,5 ; 0,6)$ \\
\hline KARAR & $\mathrm{P} 1$ & $(0,8 ; 0,9 ; 1,0 ; 1,0)$ & $(0,8 ; 0,9 ; 1,0 ; 1,0)$ & $(0,7 ; 0,8 ; 0,8 ; 0,9)$ & $(0,7 ; 0,8 ; 0,8 ; 0,9)$ \\
\hline VERİCİ & P2 & $(0,5 ; 0,6 ; 0,7 ; 0,8)$ & $(0,4 ; 0,5 ; 0,5 ; 0,6)$ & $(0,2 ; 0,3 ; 0,4 ; 0,5)$ & $(0,2 ; 0,3 ; 0,4 ; 0,5)$ \\
\hline 3 & P3 & $(0,5 ; 0,6 ; 0,7 ; 0,8)$ & $(0,4 ; 0,5 ; 0,5 ; 0,6)$ & $(0,7 ; 0,8 ; 0,8 ; 0,9)$ & $(0,2 ; 0,3 ; 0,4 ; 0,5)$ \\
\hline
\end{tabular}

Tablo7. Ayçiçek yăğ ve soya yağı tedarikçileri

\begin{tabular}{cccccc}
\hline & & \multicolumn{4}{c}{ KRITERLER } \\
\cline { 3 - 6 } & TEDARIKÇİLER & $\mathrm{C} 1$ & $\mathrm{C} 2$ & $\mathrm{C} 3$ & $\mathrm{C} 4$ \\
\cline { 2 - 6 } KARAR & $\mathrm{S} 1$ & $(0,8 ; 0,9 ; 1,0 ; 1,0)$ & $(0,4 ; 0,5 ; 0,5 ; 0,6)$ & $(0,8 ; 0,9 ; 1,0 ; 1,0)$ & $(0,4 ; 0,5 ; 0,5 ; 0,6)$ \\
VERİCI & $\mathrm{S} 2$ & $(0,5 ; 0,6 ; 0,7 ; 0,8)$ & $(0,5 ; 0,6 ; 0,7 ; 0,8)$ & $(0,5 ; 0,6 ; 0,7 ; 0,8)$ & $(0,5 ; 0,6 ; 0,7 ; 0,8)$ \\
1 & $\mathrm{~S} 3$ & $(0,1 ; 0,2 ; 0,2 ; 0,3)$ & $(0,8 ; 0,9 ; 1,0 ; 1,0)$ & $(0,4 ; 0,5 ; 0,5 ; 0,6)$ & $(0,4 ; 0,5 ; 0,5 ; 0,6)$ \\
\hline KARAR & $\mathrm{S} 1$ & $(0,7 ; 0,8 ; 0,8 ; 0,9)$ & $(0,2 ; 0,3 ; 0,4 ; 0,5)$ & $(0,7 ; 0,8 ; 0,8 ; 0,9)$ & $(0,4 ; 0,5 ; 0,5 ; 0,6)$ \\
VERİCI & $\mathrm{S} 2$ & $(0,2 ; 0,3 ; 0,4 ; 0,5)$ & $(0,4 ; 0,5 ; 0,5 ; 0,6)$ & $(0,7 ; 0,8 ; 0,8 ; 0,9)$ & $(0,4 ; 0,5 ; 0,5 ; 0,6)$ \\
2 & $\mathrm{~S} 3$ & $(0,1 ; 0,2 ; 0,2 ; 0,3)$ & $(0,2 ; 0,3 ; 0,4 ; 0,5)$ & $(0,2 ; 0,3 ; 0,4 ; 0,5)$ & $(0,4 ; 0,5 ; 0,5 ; 0,6)$ \\
\hline KARAR & $\mathrm{S} 1$ & $(0,7 ; 0,8 ; 0,8 ; 0,9)$ & $(0,7 ; 0,8 ; 0,8 ; 0,9)$ & $(0,5 ; 0,6 ; 0,7 ; 0,8)$ & $(0,5 ; 0,6 ; 0,7 ; 0,8)$ \\
VERİCI & $\mathrm{S} 2$ & $(0,5 ; 0,6 ; 0,7 ; 0,8)$ & $(0,2 ; 0,3 ; 0,4 ; 0,5)$ & $(0,0 ; 0,0 ; 0,1 ; 0,2)$ & $(0,0 ; 0,0 ; 0,1 ; 0,2)$ \\
3 & $\mathrm{~S} 3$ & $(0,7 ; 0,8 ; 0,8 ; 0,9)$ & $(0,1 ; 0,2 ; 0,2 ; 0,3)$ & $(0,5 ; 0,6 ; 0,7 ; 0,8)$ & $(0,5 ; 0,6 ; 0,7 ; 0,8)$ \\
& & & & & \\
\hline
\end{tabular}


Tablo 8. Kriter ağırlıkları

\begin{tabular}{ccccc}
\hline \multirow{2}{*}{ KARAR } & \multicolumn{4}{c}{ KRİTERLER } \\
\cline { 2 - 5 } VERİCILER & & $\mathrm{C} 2$ & $\mathrm{C} 3$ & $\mathrm{C} 4$ \\
\hline DM1 & $(0,7 ; 0,8 ; 0,8 ; 0,9)$ & $(0,7 ; 0,8 ; 0,8 ; 0,9)$ & $(0,5 ; 0,6 ; 0,7 ; 0,8)$ & $(0,2 ; 0,3 ; 0,4 ; 0,5)$ \\
DM2 & $(0,8 ; 0,9 ; 1,0 ; 1,0)$ & $(0,5 ; 0,6 ; 0,7 ; 0,8)$ & $(0,7 ; 0,8 ; 0,8 ; 0,9)$ & $(0,4 ; 0,5 ; 0,5 ; 0,6)$ \\
DM3 & $(0,7 ; 0,8 ; 0,8 ; 0,9)$ & $(0,8 ; 0,9 ; 1,0 ; 1,0)$ & $(0,5 ; 0,6 ; 0,7 ; 0,8)$ & $(0,5 ; 0,6 ; 0,7 ; 0,8)$ \\
\hline
\end{tabular}

Adım 4: Bu adımda tüm karar vericiler için genelleştirilmiş trapezoidal bulanık esnek kümeler oluşturulmuştur.

Tablo 9. Zeytinyağ 1 tedarikçileri için genelleştirilmiş trapezoidal bulanık esnek küme

\begin{tabular}{|c|c|c|c|c|c|}
\hline \multirow[t]{2}{*}{ KRİTERLER } & \multicolumn{4}{|c|}{ TEDARİKÇİLER } & \multirow{2}{*}{$\begin{array}{c}\text { TRAPEZOİAL } \\
\text { BULANIK ALT } \\
\text { KÜME }\end{array}$} \\
\hline & $\mathrm{O} 1$ & $\mathrm{O} 2$ & $\mathrm{O} 3$ & O4 & \\
\hline$(\mathrm{C} 1, \mathrm{C} 1)$ & $(0,1 ; 0,2 ; 0,2 ; 0,3)$ & $(0,4 ; 0,5 ; 0,5 ; 0,6)$ & $(0,1 ; 0,2 ; 0,2 ; 0,3)$ & $(0,1 ; 0,2 ; 0,2 ; 0,3)$ & $(0,7 ; 0,8 ; 0,8 ; 0,9)$ \\
\hline$(\mathrm{C} 1, \mathrm{C} 2)$ & $(0,4 ; 0,5 ; 0,5 ; 0,6)$ & $(0,1 ; 0,2 ; 0,2 ; 0,3)$ & $(0,2 ; 0,3 ; 0,4 ; 0,5)$ & $(0,1 ; 0,2 ; 0,2 ; 0,3)$ & $(0,7 ; 0,8 ; 0,8 ; 0,9)$ \\
\hline$(\mathrm{C} 1, \mathrm{C} 3)$ & $(0,2 ; 0,3 ; 0,4 ; 0,5)$ & $(0,5 ; 0,6 ; 0,7 ; 0,8)$ & $(0,2 ; 0,3 ; 0,4 ; 0,5)$ & $(0,1 ; 0,2 ; 0,2 ; 0,3)$ & $(0,7 ; 0,8 ; 0,8 ; 0,9)$ \\
\hline$(\mathrm{C} 1, \mathrm{C} 4)$ & $(0,4 ; 0,5 ; 0,5 ; 0,6)$ & $(0,4 ; 0,5 ; 0,5 ; 0,6)$ & $(0,2 ; 0,3 ; 0,4 ; 0,5)$ & $(0,1 ; 0,2 ; 0,2 ; 0,3)$ & $(0,7 ; 0,8 ; 0,8 ; 0,9)$ \\
\hline$(\mathrm{C} 2, \mathrm{C} 1)$ & $(0,1 ; 0,2 ; 0,2 ; 0,3)$ & $(0,4 ; 0,5 ; 0,5 ; 0,6)$ & $(0,1 ; 0,2 ; 0,2 ; 0,3)$ & $(0,0 ; 0,0 ; 0,1 ; 0,2)$ & $(0,5 ; 0,6 ; 0,7 ; 0,8)$ \\
\hline$(\mathrm{C} 2, \mathrm{C} 2)$ & $(0,2 ; 0,3 ; 0,4 ; 0,5)$ & $(0,1 ; 0,2 ; 0,2 ; 0,3)$ & $(0,2 ; 0,3 ; 0,4 ; 0,5)$ & $(0,0 ; 0,0 ; 0,1 ; 0,2)$ & $(0,5 ; 0,6 ; 0,7 ; 0,8)$ \\
\hline$(\mathrm{C} 2, \mathrm{C} 3)$ & $(0,2 ; 0,3 ; 0,4 ; 0,5)$ & $(0,4 ; 0,5 ; 0,5 ; 0,6)$ & $(0,7 ; 0,8 ; 0,8 ; 0,9)$ & $(0,0 ; 0,0 ; 0,1 ; 0,2)$ & $(0,5 ; 0,6 ; 0,7 ; 0,8)$ \\
\hline$(\mathrm{C} 2, \mathrm{C} 4)$ & $(0,2 ; 0,3 ; 0,4 ; 0,5)$ & $(0,4 ; 0,5 ; 0,5 ; 0,6)$ & $(0,7 ; 0,8 ; 0,8 ; 0,9)$ & $(0,0 ; 0,0 ; 0,1 ; 0,2)$ & $(0,5 ; 0,6 ; 0,7 ; 0,8)$ \\
\hline$(\mathrm{C} 3, \mathrm{C} 1)$ & $(0,1 ; 0,2 ; 0,2 ; 0,3)$ & $(0,4 ; 0,5 ; 0,5 ; 0,6)$ & $(0,1 ; 0,2 ; 0,2 ; 0,3)$ & $(0,1 ; 0,2 ; 0,2 ; 0,3)$ & $(0,5 ; 0,6 ; 0,7 ; 0,8)$ \\
\hline$(\mathrm{C} 3, \mathrm{C} 2)$ & $(0,2 ; 0,3 ; 0,4 ; 0,5)$ & $(0,1 ; 0,2 ; 0,2 ; 0,3)$ & $(0,2 ; 0,3 ; 0,4 ; 0,5)$ & $(0,1 ; 0,2 ; 0,2 ; 0,3)$ & $(0,5 ; 0,6 ; 0,7 ; 0,8)$ \\
\hline (C3, C3) & $(0,2 ; 0,3 ; 0,4 ; 0,5)$ & $(0,4 ; 0,5 ; 0,5 ; 0,6)$ & $(0,5 ; 0,6 ; 0,7 ; 0,8)$ & $(0,1 ; 0,2 ; 0,2 ; 0,3)$ & $(0,5 ; 0,6 ; 0,7 ; 0,8)$ \\
\hline$(\mathrm{C} 3, \mathrm{C} 4)$ & $(0,2 ; 0,3 ; 0,4 ; 0,5)$ & $(0,4 ; 0,5 ; 0,5 ; 0,6)$ & $(0,5 ; 0,6 ; 0,7 ; 0,8)$ & $(0,1 ; 0,2 ; 0,2 ; 0,3)$ & $(0,5 ; 0,6 ; 0,7 ; 0,8)$ \\
\hline$(\mathrm{C} 4, \mathrm{C} 1)$ & $(0,1 ; 0,2 ; 0,2 ; 0,3)$ & $(0,4 ; 0,5 ; 0,5 ; 0,6)$ & $(0,1 ; 0,2 ; 0,2 ; 0,3)$ & $(0,2 ; 0,3 ; 0,4 ; 0,5)$ & $(0,2 ; 0,3 ; 0,4 ; 0,5)$ \\
\hline$(\mathrm{C} 4, \mathrm{C} 2)$ & $(0,4 ; 0,5 ; 0,5 ; 0,6)$ & $(0,1 ; 0,2 ; 0,2 ; 0,3)$ & $(0,2 ; 0,3 ; 0,4 ; 0,5)$ & $(0,1 ; 0,2 ; 0,2 ; 0,3)$ & $(0,2 ; 0,3 ; 0,4 ; 0,5)$ \\
\hline$(\mathrm{C} 4, \mathrm{C} 3)$ & $(0,2 ; 0,3 ; 0,4 ; 0,5)$ & $(0,5 ; 0,6 ; 0,7 ; 0,8)$ & $(0,7 ; 0,8 ; 0,8 ; 0,9)$ & $(0,2 ; 0,3 ; 0,4 ; 0,5)$ & $(0,2 ; 0,3 ; 0,4 ; 0,5)$ \\
\hline$(\mathrm{C} 4, \mathrm{C} 4)$ & $(0,4 ; 0,5 ; 0,5 ; 0,6)$ & $(0,4 ; 0,5 ; 0,5 ; 0,6)$ & $(0,7 ; 0,8 ; 0,8 ; 0,9)$ & $(0,2 ; 0,3 ; 0,4 ; 0,5)$ & $(0,2 ; 0,3 ; 0,4 ; 0,5)$ \\
\hline
\end{tabular}

Tablo 10. Palm yağı tedarikçileri için genelleştirilmiş trapezoidal bulanık esnek küme

\begin{tabular}{|c|c|c|c|c|}
\hline \multirow[t]{2}{*}{ KRİTERLER } & \multicolumn{3}{|c|}{ TEDARİKÇİLER } & \multirow{2}{*}{$\begin{array}{c}\text { TRAPEZOİDAL } \\
\text { BULANIK ALT } \\
\text { KÜME }\end{array}$} \\
\hline & $\mathrm{P} 1$ & $\mathrm{P} 2$ & P3 & \\
\hline$(\mathrm{C} 1, \mathrm{C} 1)$ & $(0,7 ; 0,8 ; 0,8 ; 0,9)$ & $(0,1 ; 0,2 ; 0,2 ; 0,3)$ & $(0,4 ; 0,5 ; 0,5 ; 0,6)$ & $(0,7 ; 0,8 ; 0,8 ; 0,9)$ \\
\hline$(\mathrm{C} 1, \mathrm{C} 2)$ & $(0,5 ; 0,6 ; 0,7 ; 0,8)$ & $(0,1 ; 0,2 ; 0,2 ; 0,3)$ & $(0,4 ; 0,5 ; 0,5 ; 0,6)$ & $(0,7 ; 0,8 ; 0,8 ; 0,9)$ \\
\hline$(\mathrm{C} 1, \mathrm{C} 3)$ & $(0,5 ; 0,6 ; 0,7 ; 0,8)$ & $(0,1 ; 0,2 ; 0,2 ; 0,3)$ & $(0,5 ; 0,6 ; 0,7 ; 0,8)$ & $(0,7 ; 0,8 ; 0,8 ; 0,9)$ \\
\hline$(\mathrm{C} 1, \mathrm{C} 4)$ & $(0,5 ; 0,6 ; 0,7 ; 0,8)$ & $(0,1 ; 0,2 ; 0,2 ; 0,3)$ & $(0,2 ; 0,3 ; 0,4 ; 0,5)$ & $(0,7 ; 0,8 ; 0,8 ; 0,9)$ \\
\hline$(\mathrm{C} 2, \mathrm{C} 1)$ & $(0,5 ; 0,6 ; 0,7 ; 0,8)$ & $(0,1 ; 0,2 ; 0,2 ; 0,3)$ & $(0,4 ; 0,5 ; 0,5 ; 0,6)$ & $(0,5 ; 0,6 ; 0,7 ; 0,8)$ \\
\hline$(\mathrm{C} 2, \mathrm{C} 2)$ & $(0,5 ; 0,6 ; 0,7 ; 0,8)$ & $(0,1 ; 0,2 ; 0,2 ; 0,3)$ & $(0,4 ; 0,5 ; 0,5 ; 0,6)$ & $(0,5 ; 0,6 ; 0,7 ; 0,8)$ \\
\hline$(\mathrm{C} 2, \mathrm{C} 3)$ & $(0,5 ; 0,6 ; 0,7 ; 0,8)$ & $(0,1 ; 0,2 ; 0,2 ; 0,3)$ & $(0,4 ; 0,5 ; 0,5 ; 0,6)$ & $(0,5 ; 0,6 ; 0,7 ; 0,8)$ \\
\hline$(\mathrm{C} 2, \mathrm{C} 4)$ & $(0,5 ; 0,6 ; 0,7 ; 0,8)$ & $(0,1 ; 0,2 ; 0,2 ; 0,3)$ & $(0,2 ; 0,3 ; 0,4 ; 0,5)$ & $(0,5 ; 0,6 ; 0,7 ; 0,8)$ \\
\hline$(\mathrm{C} 3, \mathrm{C} 1)$ & $(0,5 ; 0,6 ; 0,7 ; 0,8)$ & $(0,1 ; 0,2 ; 0,2 ; 0,3)$ & $(0,4 ; 0,5 ; 0,5 ; 0,6)$ & $(0,5 ; 0,6 ; 0,7 ; 0,8)$ \\
\hline$(\mathrm{C} 3, \mathrm{C} 2)$ & $(0,5 ; 0,6 ; 0,7 ; 0,8)$ & $(0,1 ; 0,2 ; 0,2 ; 0,3)$ & $(0,4 ; 0,5 ; 0,5 ; 0,6)$ & $(0,5 ; 0,6 ; 0,7 ; 0,8)$ \\
\hline$(\mathrm{C} 3, \mathrm{C} 3)$ & $(0,5 ; 0,6 ; 0,7 ; 0,8)$ & $(0,1 ; 0,2 ; 0,2 ; 0,3)$ & $(0,4 ; 0,5 ; 0,5 ; 0,6)$ & $(0,5 ; 0,6 ; 0,7 ; 0,8)$ \\
\hline$(\mathrm{C} 3, \mathrm{C} 4)$ & $(0,5 ; 0,6 ; 0,7 ; 0,8)$ & $(0,1 ; 0,2 ; 0,2 ; 0,3)$ & $(0,2 ; 0,3 ; 0,4 ; 0,5)$ & $(0,5 ; 0,6 ; 0,7 ; 0,8)$ \\
\hline$(\mathrm{C} 4, \mathrm{C} 1)$ & $(0,7 ; 0,8 ; 0,8 ; 0,9)$ & $(0,1 ; 0,2 ; 0,2 ; 0,3)$ & $(0,4 ; 0,5 ; 0,5 ; 0,6)$ & $(0,2 ; 0,3 ; 0,4 ; 0,5)$ \\
\hline$(\mathrm{C} 4, \mathrm{C} 2)$ & $(0,5 ; 0,6 ; 0,7 ; 0,8)$ & $(0,1 ; 0,2 ; 0,2 ; 0,3)$ & $(0,4 ; 0,5 ; 0,5 ; 0,6)$ & $(0,2 ; 0,3 ; 0,4 ; 0,5)$ \\
\hline$(\mathrm{C} 4, \mathrm{C} 3)$ & $(0,5 ; 0,6 ; 0,7 ; 0,8)$ & $(0,1 ; 0,2 ; 0,2 ; 0,3)$ & $(0,5 ; 0,6 ; 0,7 ; 0,8)$ & $(0,2 ; 0,3 ; 0,4 ; 0,5)$ \\
\hline$(\mathrm{C} 4, \mathrm{C} 4)$ & $(0,5 ; 0,6 ; 0,7 ; 0,8)$ & $(0,1 ; 0,2 ; 0,2 ; 0,3)$ & $(0,2 ; 0,3 ; 0,4 ; 0,5)$ & $(0,2 ; 0,3 ; 0,4 ; 0,5)$ \\
\hline
\end{tabular}


Tablo 11. Ayçiçek yağı ve soya yağı tedarikçileri için genelleştirilmiş trapezoidal bulanık esnek küme

\begin{tabular}{|c|c|c|c|c|}
\hline \multirow[t]{2}{*}{ KRİTERLER } & \multicolumn{3}{|c|}{ TEDARİKÇİLER } & \multirow{2}{*}{$\begin{array}{c}\text { TRAPEZOİDAL } \\
\text { BULANIK ALT } \\
\text { KÜME }\end{array}$} \\
\hline & S1 & S2 & S3 & \\
\hline$(\mathrm{C} 1, \mathrm{C} 1)$ & $(0,7 ; 0,8 ; 0,8 ; 0,9)$ & $(0,2 ; 0,3 ; 0,4 ; 0,5)$ & $(0,1 ; 0,2 ; 0,2 ; 0,3)$ & $(0,7 ; 0,8 ; 0,8 ; 0,9)$ \\
\hline$(\mathrm{C} 1, \mathrm{C} 2)$ & $(0,2 ; 0,3 ; 0,4 ; 0,5)$ & $(0,2 ; 0,3 ; 0,4 ; 0,5)$ & $(0,1 ; 0,2 ; 0,2 ; 0,3)$ & $(0,7 ; 0,8 ; 0,8 ; 0,9)$ \\
\hline$(\mathrm{C} 1, \mathrm{C} 3)$ & $(0,5 ; 0,6 ; 0,7 ; 0,8)$ & $(0,0 ; 0,0 ; 0,1 ; 0,2)$ & $(0,1 ; 0,2 ; 0,2 ; 0,3)$ & $(0,7 ; 0,8 ; 0,8 ; 0,9)$ \\
\hline$(\mathrm{C} 1, \mathrm{C} 4)$ & $(0,4 ; 0,5 ; 0,5 ; 0,6)$ & $(0,0 ; 0,0 ; 0,1 ; 0,2)$ & $(0,1 ; 0,2 ; 0,2 ; 0,3)$ & $(0,7 ; 0,8 ; 0,8 ; 0,9)$ \\
\hline$(\mathrm{C} 2, \mathrm{C} 1)$ & $(0,4 ; 0,5 ; 0,5 ; 0,6)$ & $(0,2 ; 0,3 ; 0,4 ; 0,5)$ & $(0,1 ; 0,2 ; 0,2 ; 0,3)$ & $(0,5 ; 0,6 ; 0,7 ; 0,8)$ \\
\hline$(\mathrm{C} 2, \mathrm{C} 2)$ & $(0,2 ; 0,3 ; 0,4 ; 0,5)$ & $(0,2 ; 0,3 ; 0,4 ; 0,5)$ & $(0,1 ; 0,2 ; 0,2 ; 0,3)$ & $(0,5 ; 0,6 ; 0,7 ; 0,8)$ \\
\hline$(\mathrm{C} 2, \mathrm{C} 3)$ & $(0,4 ; 0,5 ; 0,5 ; 0,6)$ & $(0,0 ; 0,0 ; 0,1 ; 0,2)$ & $(0,2 ; 0,3 ; 0,4 ; 0,5)$ & $(0,5 ; 0,6 ; 0,7 ; 0,8)$ \\
\hline$(\mathrm{C} 2, \mathrm{C} 4)$ & $(0,4 ; 0,5 ; 0,5 ; 0,6)$ & $(0,0 ; 0,0 ; 0,1 ; 0,2)$ & $(0,4 ; 0,5 ; 0,5 ; 0,6)$ & $(0,5 ; 0,6 ; 0,7 ; 0,8)$ \\
\hline$(\mathrm{C} 3, \mathrm{C} 1)$ & $(0,7 ; 0,8 ; 0,8 ; 0,9)$ & $(0,2 ; 0,3 ; 0,4 ; 0,5)$ & $(0,1 ; 0,2 ; 0,2 ; 0,3)$ & $(0,5 ; 0,6 ; 0,7 ; 0,8)$ \\
\hline$(\mathrm{C} 3, \mathrm{C} 2)$ & $(0,2 ; 0,3 ; 0,4 ; 0,5)$ & $(0,2 ; 0,3 ; 0,4 ; 0,5)$ & $(0,1 ; 0,2 ; 0,2 ; 0,3)$ & $(0,5 ; 0,6 ; 0,7 ; 0,8)$ \\
\hline$(\mathrm{C} 3, \mathrm{C} 3)$ & $(0,5 ; 0,6 ; 0,7 ; 0,8)$ & $(0,0 ; 0,0 ; 0,1 ; 0,2)$ & $(0,2 ; 0,3 ; 0,4 ; 0,5)$ & $(0,5 ; 0,6 ; 0,7 ; 0,8)$ \\
\hline$(\mathrm{C} 3, \mathrm{C} 4)$ & $(0,4 ; 0,5 ; 0,5 ; 0,6)$ & $(0,0 ; 0,0 ; 0,1 ; 0,2)$ & $(0,4 ; 0,5 ; 0,5 ; 0,6)$ & $(0,5 ; 0,6 ; 0,7 ; 0,8)$ \\
\hline$(\mathrm{C} 4, \mathrm{C} 1)$ & $(0,4 ; 0,5 ; 0,5 ; 0,6)$ & $(0,2 ; 0,3 ; 0,4 ; 0,5)$ & $(0,1 ; 0,2 ; 0,2 ; 0,3)$ & $(0,2 ; 0,3 ; 0,4 ; 0,5)$ \\
\hline$(\mathrm{C} 4, \mathrm{C} 2)$ & $(0,2 ; 0,3 ; 0,4 ; 0,5)$ & $(0,2 ; 0,3 ; 0,4 ; 0,5)$ & $(0,1 ; 0,2 ; 0,2 ; 0,3)$ & $(0,2 ; 0,3 ; 0,4 ; 0,5)$ \\
\hline$(\mathrm{C} 4, \mathrm{C} 3)$ & $(0,4 ; 0,5 ; 0,5 ; 0,6)$ & $(0,0 ; 0,0 ; 0,1 ; 0,2)$ & $(0,2 ; 0,3 ; 0,4 ; 0,5)$ & $(0,2 ; 0,3 ; 0,4 ; 0,5)$ \\
\hline$(\mathrm{C} 4, \mathrm{C} 4)$ & $(0,4 ; 0,5 ; 0,5 ; 0,6)$ & $(0,0 ; 0,0 ; 0,1 ; 0,2)$ & $(0,4 ; 0,5 ; 0,5 ; 0,6)$ & $(0,2 ; 0,3 ; 0,4 ; 0,5)$ \\
\hline
\end{tabular}

Adım 5: Bu adımda durulaştırılmış değerler çizelgesi hazırlanmıştır.

Tablo 12. Zeytinyağı tedarikçileri için durulaştırılmış değerler çizelgesi

\begin{tabular}{ccccccccc}
\hline TEDARIKÇiLER & $(\mathrm{C} 1, \mathrm{C} 1)$ & $(\mathrm{C} 1, \mathrm{C} 2)$ & $(\mathrm{C} 1, \mathrm{C} 3)$ & $(\mathrm{C} 1, \mathrm{C} 4)$ & $(\mathrm{C} 2, \mathrm{C} 1)$ & $(\mathrm{C} 2, \mathrm{C} 2)$ & $(\mathrm{C} 2, \mathrm{C} 3)$ & $(\mathrm{C} 2, \mathrm{C} 4)$ \\
\hline O1 & 0,200 & 0,500 & 0,350 & 0,500 & 0,200 & 0,350 & 0,350 & 0,350 \\
O2 & 0,500 & 0,200 & 0,650 & 0,500 & 0,500 & 0,200 & 0,500 & 0,500 \\
O3 & 0,200 & 0,350 & 0,350 & 0,350 & 0,200 & 0,350 & 0,800 & 0,800 \\
O4 & 0,200 & 0,200 & 0,200 & 0,200 & 0,075 & 0,075 & 0,075 & 0,075 \\
$\lambda$ & 0,800 & 0,800 & 0,800 & 0,800 & 0,650 & 0,650 & 0,650 & 0,650 \\
TEDARIKÇILER & $(\mathrm{C} 3, \mathrm{C} 1)$ & $(\mathrm{C} 3, \mathrm{C} 2)$ & $(\mathrm{C} 3, \mathrm{C} 3)$ & $(\mathrm{C} 3, \mathrm{C} 4)$ & $(\mathrm{C} 4, \mathrm{C} 1)$ & $(\mathrm{C} 4, \mathrm{C} 2)$ & $(\mathrm{C} 4, \mathrm{C} 3)$ & $(\mathrm{C} 4, \mathrm{C} 4)$ \\
O1 & 0,200 & 0,350 & 0,350 & 0,350 & 0,200 & 0,500 & 0,350 & 0,500 \\
O2 & 0,500 & 0,200 & 0,500 & 0,500 & 0,500 & 0,200 & 0,650 & 0,500 \\
O3 & 0,200 & 0,350 & 0,650 & 0,650 & 0,200 & 0,350 & 0,800 & 0,800 \\
O4 & 0,200 & 0,200 & 0,200 & 0,200 & 0,350 & 0,200 & 0,350 & 0,350 \\
$\lambda$ & 0,650 & 0,650 & 0,650 & 0,650 & 0,350 & 0,350 & 0,350 & 0,350 \\
\hline
\end{tabular}

Tablo 13. Palm yağ tedarikçileri için durulaştırılmış değerler çizelgesi

\begin{tabular}{ccccccccc}
\hline TEDARIKÇILER & $(\mathrm{C} 1, \mathrm{C} 1)$ & $(\mathrm{C} 1, \mathrm{C} 2)$ & $(\mathrm{C} 1, \mathrm{C} 3)$ & $(\mathrm{C} 1, \mathrm{C} 4)$ & $(\mathrm{C} 2, \mathrm{C} 1)$ & $(\mathrm{C} 2, \mathrm{C} 2)$ & $(\mathrm{C} 2, \mathrm{C} 3)$ & $(\mathrm{C} 2, \mathrm{C} 4)$ \\
\hline P1 & 0,800 & 0,650 & 0,650 & 0,650 & 0,650 & 0,650 & 0,650 & 0,650 \\
P2 & 0,200 & 0,200 & 0,200 & 0,200 & 0,200 & 0,200 & 0,200 & 0,200 \\
P3 & 0,500 & 0,500 & 0,650 & 0,350 & 0,500 & 0,500 & 0,500 & 0,350 \\
$\lambda$ & 0,800 & 0,800 & 0,800 & 0,800 & 0,650 & 0,650 & 0,650 & 0,650 \\
TEDARIKÇILER & $(\mathrm{C} 3, \mathrm{C} 1)$ & $(\mathrm{C} 3, \mathrm{C} 2)$ & $(\mathrm{C} 3, \mathrm{C} 3)$ & $(\mathrm{C} 3, \mathrm{C} 4)$ & $(\mathrm{C} 4, \mathrm{C} 1)$ & $(\mathrm{C} 4, \mathrm{C} 2)$ & $(\mathrm{C} 4, \mathrm{C} 3)$ & $(\mathrm{C} 4, \mathrm{C} 4)$ \\
P1 & 0,650 & 0,650 & 0,650 & 0,650 & 0,800 & 0,650 & 0,650 & 0,650 \\
P2 & 0,200 & 0,200 & 0,200 & 0,200 & 0,200 & 0,200 & 0,200 & 0,200 \\
P3 & 0,500 & 0,500 & 0,500 & 0,350 & 0,500 & 0,500 & 0,650 & 0,350 \\
$\lambda$ & 0,650 & 0,650 & 0,650 & 0,650 & 0,350 & 0,350 & 0,350 & 0,350 \\
\hline
\end{tabular}

Tablo 14. Ayçiçek yağı ve soya yağı tedarikçileri için durulaştırılmış değerler çizelgesi

\begin{tabular}{ccccccccc}
\hline TEDARIKÇILER & $(\mathrm{C} 1, \mathrm{C} 1)$ & $(\mathrm{C} 1, \mathrm{C} 2)$ & $(\mathrm{C} 1, \mathrm{C} 3)$ & $(\mathrm{C} 1, \mathrm{C} 4)$ & $(\mathrm{C} 2, \mathrm{C} 1)$ & $(\mathrm{C} 2, \mathrm{C} 2)$ & $(\mathrm{C} 2, \mathrm{C} 3)$ & $(\mathrm{C} 2, \mathrm{C} 4)$ \\
\hline S1 & 0,800 & 0,350 & 0,650 & 0,500 & 0,500 & 0,350 & 0,500 & 0,500 \\
S2 & 0,350 & 0,350 & 0,075 & 0,075 & 0,350 & 0,350 & 0,075 & 0,075 \\
S3 & 0,200 & 0,200 & 0,200 & 0,200 & 0,200 & 0,200 & 0,350 & 0,500 \\
$\lambda$ & 0,800 & 0,800 & 0,800 & 0,800 & 0,650 & 0,650 & 0,650 & 0,650 \\
\hline
\end{tabular}


Tablo 14. Ayçiçek yağı ve soya yağı tedarikçileri için durulaştırılmış değerler çizelgesi

(devami)

\begin{tabular}{ccccccccc}
\hline TEDARIKÇILER & $(\mathrm{C} 3, \mathrm{C} 1)$ & $(\mathrm{C} 3, \mathrm{C} 2)$ & $(\mathrm{C} 3, \mathrm{C} 3)$ & $(\mathrm{C} 3, \mathrm{C} 4)$ & $(\mathrm{C} 4, \mathrm{C} 1)$ & $(\mathrm{C} 4, \mathrm{C} 2)$ & $(\mathrm{C} 4, \mathrm{C} 3)$ & $(\mathrm{C} 4, \mathrm{C} 4)$ \\
\hline S1 & 0,800 & 0,350 & 0,650 & 0,500 & 0,500 & 0,350 & 0,500 & 0,500 \\
S2 & 0,350 & 0,350 & 0,075 & 0,075 & 0,350 & 0,350 & 0,075 & 0,075 \\
S3 & 0,200 & 0,200 & 0,350 & 0,500 & 0,200 & 0,200 & 0,350 & 0,500 \\
$\lambda$ & 0,650 & 0,650 & 0,650 & 0,650 & 0,350 & 0,350 & 0,350 & 0,350 \\
\hline
\end{tabular}

Adım 6: $\mathrm{Bu}$ adımda durulaştırılmış dereceler çizelgesi hazırlanmıştır.

Tablo 15. Zeytinyağı tedarikçileri için durulaştırılmış dereceler çizelgesi

\begin{tabular}{ccccccccc}
\hline TEDARIKÇíLER & $(\mathrm{C} 1, \mathrm{C} 1)$ & $(\mathrm{C} 1, \mathrm{C} 2)$ & $(\mathrm{C} 1, \mathrm{C} 3)$ & $(\mathrm{C} 1, \mathrm{C} 4)$ & $(\mathrm{C} 2, \mathrm{C} 1)$ & $(\mathrm{C} 2, \mathrm{C} 2)$ & $(\mathrm{C} 2, \mathrm{C} 3)$ & $(\mathrm{C} 2, \mathrm{C} 4)$ \\
\hline $\mathrm{O}_{1}$ & $\mathrm{O} 2$ & $\mathrm{O} 1$ & $\mathrm{O} 2$ & $\mathrm{O} 1, \mathrm{O} 2$ & $\mathrm{O} 2$ & $\mathrm{O} 1, \mathrm{O} 3$ & $\mathrm{O} 3$ & $\mathrm{O} 3$ \\
$\mathrm{YD}$ & 0,500 & 0,500 & 0,650 & 0,500 & 0,500 & 0,350 & 0,800 & 0,800 \\
$\mathrm{OD}$ & 0,800 & 0,800 & 0,800 & 0,800 & 0,650 & 0,650 & 0,650 & 0,650 \\
\hline
\end{tabular}

Tablo 15. Zeytinyağı tedarikçileri için durulaştırılmış dereceler çizelgesi (devamı)

\begin{tabular}{ccccccccc}
\hline TEDARIKÇiLER & $(\mathrm{C} 3, \mathrm{C} 1)$ & $(\mathrm{C} 3, \mathrm{C} 2)$ & $(\mathrm{C} 3, \mathrm{C} 3)$ & $(\mathrm{C} 3, \mathrm{C} 4)$ & $(\mathrm{C} 4, \mathrm{C} 1)$ & $(\mathrm{C} 4, \mathrm{C} 2)$ & $(\mathrm{C} 4, \mathrm{C} 3)$ & $(\mathrm{C} 4, \mathrm{C} 4)$ \\
\hline Oi & $\mathrm{O} 2$ & $\mathrm{O} 1, \mathrm{O} 3$ & $\mathrm{O} 3$ & $\mathrm{O} 3$ & $\mathrm{O} 2$ & $\mathrm{O} 1$ & $\mathrm{O} 3$ & $\mathrm{O} 3$ \\
YD & 0,500 & 0,350 & 0,650 & 0,650 & 0,500 & 0,500 & 0,800 & 0,800 \\
OD & 0,650 & 0,650 & 0,650 & 0,650 & 0,350 & 0,350 & 0,350 & 0,350 \\
\hline
\end{tabular}

Tablo 16. Palm yağı tedarikçileri için durulaştırılmış dereceler çizelgesi

\begin{tabular}{ccccccccc}
\hline TEDARIKÇiLER & $(\mathrm{C} 1, \mathrm{C} 1)$ & $(\mathrm{C} 1, \mathrm{C} 2)$ & $(\mathrm{C} 1, \mathrm{C} 3)$ & $(\mathrm{C} 1, \mathrm{C} 4)$ & $(\mathrm{C} 2, \mathrm{C} 1)$ & $(\mathrm{C} 2, \mathrm{C} 2)$ & $(\mathrm{C} 2, \mathrm{C} 3)$ & $(\mathrm{C} 2, \mathrm{C} 4)$ \\
\hline Pi & $\mathrm{P} 1$ & $\mathrm{P} 1$ & $\mathrm{P} 1, \mathrm{P} 3$ & $\mathrm{P} 1$ & $\mathrm{P} 1$ & $\mathrm{P} 1$ & $\mathrm{P} 1$ & $\mathrm{P} 1$ \\
YD & 0,800 & 0,650 & 0,650 & 0,650 & 0,650 & 0,650 & 0,650 & 0,650 \\
OD & 0,800 & 0,800 & 0,800 & 0,800 & 0,650 & 0,650 & 0,650 & 0,650 \\
\hline
\end{tabular}

Tablo 16. Palm yağ tedarikçileri için durulaştırılmış dereceler çizelgesi (devamı)

\begin{tabular}{ccccccccc}
\hline TEDARIKÇiLER & $(\mathrm{C} 3, \mathrm{C} 1)$ & $(\mathrm{C} 3, \mathrm{C} 2)$ & $(\mathrm{C} 3, \mathrm{C} 3)$ & $(\mathrm{C} 3, \mathrm{C} 4)$ & $(\mathrm{C} 4, \mathrm{C} 1)$ & $(\mathrm{C} 4, \mathrm{C} 2)$ & $(\mathrm{C} 4, \mathrm{C} 3)$ & $(\mathrm{C} 4, \mathrm{C} 4)$ \\
\hline $\mathrm{P} 1$ & $\mathrm{P} 1$ & $\mathrm{P} 1$ & $\mathrm{P} 1$ & $\mathrm{P} 1$ & $\mathrm{P} 1$ & $\mathrm{P} 1$ & $\mathrm{P} 1, \mathrm{P} 3$ & $\mathrm{P} 1$ \\
$\mathrm{YD}$ & 0,650 & 0,650 & 0,650 & 0,650 & 0,800 & 0,650 & 0,650 & 0,650 \\
$\mathrm{OD}$ & 0,650 & 0,650 & 0,650 & 0,650 & 0,350 & 0,350 & 0,350 & 0,350 \\
\hline
\end{tabular}

Tablo 17. Ayçiçek yağı ve soya yağı tedarikçileri için durulaştırılmış dereceler çizelgesi

\begin{tabular}{ccccccccc}
\hline TEDARIKÇiLER & $(\mathrm{C} 1, \mathrm{C} 1)$ & $(\mathrm{C} 1, \mathrm{C} 2)$ & $(\mathrm{C} 1, \mathrm{C} 3)$ & $(\mathrm{C} 1, \mathrm{C} 4)$ & $(\mathrm{C} 2, \mathrm{C} 1)$ & $(\mathrm{C} 2, \mathrm{C} 2)$ & $(\mathrm{C} 2, \mathrm{C} 3)$ & $(\mathrm{C} 2, \mathrm{C} 4)$ \\
\hline $\mathrm{P} 1$ & $\mathrm{~S} 1$ & $\mathrm{~S} 1, \mathrm{~S} 2$ & $\mathrm{~S} 1$ & $\mathrm{~S} 1$ & $\mathrm{~S} 1$ & $\mathrm{~S} 1, \mathrm{~S} 2$ & $\mathrm{~S} 1$ & $\mathrm{~S} 1, \mathrm{~S} 3$ \\
$\mathrm{YD}$ & 0,800 & 0,350 & 0,650 & 0,500 & 0,500 & 0,350 & 0,500 & 0,500 \\
$\mathrm{OD}$ & 0,800 & 0,800 & 0,800 & 0,800 & 0,650 & 0,650 & 0,650 & 0,650 \\
\hline
\end{tabular}

Tablo 17. Ayçiçek yağı ve soya yağı tedarikçileri için durulaştırılmış dereceler çizelgesi (devami)

\begin{tabular}{ccccccccc}
\hline TEDARIKÇiLER & $(\mathrm{C} 3, \mathrm{C} 1)$ & $(\mathrm{C} 3, \mathrm{C} 2)$ & $(\mathrm{C} 3, \mathrm{C} 3)$ & $(\mathrm{C} 3, \mathrm{C} 4)$ & $(\mathrm{C} 4, \mathrm{C} 1)$ & $(\mathrm{C} 4, \mathrm{C} 2)$ & $(\mathrm{C} 4, \mathrm{C} 3)$ & $(\mathrm{C} 4, \mathrm{C} 4)$ \\
\hline $\mathrm{P} 1$ & $\mathrm{~S} 1$ & $\mathrm{~S} 1, \mathrm{~S} 2$ & $\mathrm{~S} 1$ & $\mathrm{~S} 1, \mathrm{~S} 3$ & $\mathrm{~S} 1$ & $\mathrm{~S} 1, \mathrm{~S} 2$ & $\mathrm{~S} 1$ & $\mathrm{~S} 1, \mathrm{~S} 3$ \\
$\mathrm{YD}$ & 0,800 & 0,350 & 0,650 & 0,500 & 0,500 & 0,350 & 0,500 & 0,500 \\
$\mathrm{OD}$ & 0,650 & 0,650 & 0,650 & 0,650 & 0,350 & 0,350 & 0,350 & 0,350 \\
\hline
\end{tabular}

Adım 7: Bu adımda toplam puanlar hesaplanmıştır ve alternatiflerin sıralanması yapılmıştır. 
Tablo 18. Tedarikçiler için toplam puanlar ve tedarikçilerin sıralanmas1

\begin{tabular}{|c|c|c|c|c|c|}
\hline \multicolumn{2}{|c|}{ Zeytinyağı Tedarikçileri } & \multicolumn{2}{|c|}{ Palm Yağı Tedarikçileri } & \multicolumn{2}{|c|}{$\begin{array}{c}\text { Ayçiçek Yağ1 ve Soya Yağ } \\
\text { Tedarikçileri }\end{array}$} \\
\hline Tedarikçi & Toplam Puan & Tedarikçi & Toplam Puan & Tedarikçi & $\begin{array}{l}\text { Toplam } \\
\text { Puan }\end{array}$ \\
\hline O1 & 1,2025 & $\mathrm{P} 1$ & 4,4075 & S1 & 3,7200 \\
\hline $\mathrm{O} 2$ & 1,7450 & P2 & 0,0000 & S2 & 0,6300 \\
\hline $\mathrm{O} 3$ & 1,9700 & P3 & 0,7475 & S3 & 0,6500 \\
\hline $\mathrm{O} 4$ & 0,000 & & & & \\
\hline \multicolumn{6}{|c|}{ Siralamalar } \\
\hline \multicolumn{2}{|c|}{$\mathrm{O} 3, \mathrm{O} 2, \mathrm{O} 1, \mathrm{O} 4$} & \multicolumn{2}{|c|}{$\mathrm{P} 1, \mathrm{P} 3, \mathrm{P} 2$} & \multicolumn{2}{|c|}{$\mathrm{S} 1, \mathrm{~S} 3, \mathrm{~S} 2$} \\
\hline
\end{tabular}

\section{Sonuç ve Öneriler}

Organizasyonların ürün ya da hizmet kalitelerini geliştirilebilmeleri ve toplam maliyetlerini kontrol altında tutabilmeleri için, tedarikçilerin değerlendirilmesi ve seçimi stratejik kararlar arasında yer almaktadır. Son yıllarda çevre bilincinin ve çevrenin korunmasına yönelik uygulamaların artması sebebiyle organizasyonların ve organizasyonların içinde yer aldığı tedarik zincirlerinin çevreci uygulamalarını zorunlu hale getirmiştir. Bu uygulamaların bir parçası olan yeşil tedarikçi seçimi, geleneksel tedarikçi seçimi yaklaşımları ile bütünleştirilerek, tedarikçilerin değerlendirilmesinde ve seçiminde fiyat, kalite, esneklik, hız, kapasite, hizmet düzeyi gibi faktörlerle birlikte karbon emisyonu, karbon ayak izi, enerji tüketimi ve verimliliği, su tüketimi, katı, sıvı ya da gaz atıkların düzeyi, geri dönüşüm girişimleri, çevreci ambalajların tercih edilmesi gibi faktörlerin de kullanılmasına yol açmıştır. Tedarikçilerin değerlendirilmesi ve seçiminde kalitatif ve kantitatif çok sayıda kriterin dikkate alınması sebebiyle bu problemler çok kriterli karar verme problemleri olarak tanımlanmaktadır ve bu türdeki problemlerin çözümü için genellikle çok kriterli karar verme tekniklerinden faydalanılmaktadır.

Bulanık teori, genellikle dilsel terimlerle ifade edilen kesin olmayan ve belirsiz bilgilerin olması durumunda karar verme yetenekleri sağlamak için geliştirilmiş̧ir. Trapezoidal bulanık esnek kümeler kesin olmayan ya da belirsiz bilgilerin etkili bir şekilde dilsel değişkenler olarak tanımlanabilmesine imkân tanımaktadır. Bu çalışmada genelleştirilmiş trapezoidal bulanık esnek kümelerin, çok kriterli karar verme problemlerinin çözümü için kullanılabileceği düşüncesinden hareketle trapezoidal bulanık esnek kümeler yeşil tedarikçi seçimi problemine uygulanmıştır. Bu amaçla Banaeian vd. (2018) tarafindan yapılan çalışmanın verileri kullanılarak analizler gerçekleştirilmiştir. Banaeian vd. yeşil tedarikçi değerlendirmesi ve seçimi için çalışma verilerini üçgen bulanık sayılara dönüştürmüşler ve bulanık TOPSIS, bulanık VIKOR ve bulanık GRA yöntemlerini ayrı ayıı kullanarak, sıralama sonuçlarını karşılaştırmışlardır. Her üç yöntemde de sıralamalar zeytinyağ 1 tedarikçileri için $\left(\mathrm{O}_{3}, \mathrm{O}_{2}, \mathrm{O}_{1}, \mathrm{O}_{4}\right)$, palm yağ tedarikçileri için $\left(\mathrm{P}_{1}, \mathrm{P}_{3}, \mathrm{P}_{2}\right)$, ayçiçek yağ1 ve soya yağı tedarikçileri için $\left(\mathrm{SS}_{1}, \mathrm{SS}_{3}, \mathrm{SS}_{2}\right)$ şekilde gerçekleşmiştir. Çalışma kapsamında öncelikle alternatiflerin kriterler açısından dilsel değerlendirmeleri trapezoidal sayılara dönüştürülmüştür. Daha sonra problem genelleştirilmiş trapezoidal bulanık esnek kümeler kullanılarak çözüldüğünde de tedarikçilerin sıralamasında herhangi bir değişiklik olmadığı yani sıralamanın yine zeytinyağ 1 tedarikçileri için $\left(\mathrm{O}_{3}, \mathrm{O}_{2}, \mathrm{O}_{1}, \mathrm{O}_{4}\right)$, palm yağ tedarikçileri için $\left(\mathrm{P}_{1}, \mathrm{P}_{3}, \mathrm{P}_{2}\right)$, ayçiçek yağı ve soya yağ tedarikçileri için $\left(\mathrm{SS}_{1}, \mathrm{SS}_{3}, \mathrm{SS}_{2}\right)$ şeklinde olduğu görülmüştür. Bu nedenle, genelleştirilmiş trapezoidal bulanık esnek kümelerin çok kriterli karar verme tekniklerine alternatif oluşturabileceği söylenebilir.

\section{Kaynakça}

Ahmad, B. ve Kharal, A. (2009). On fuzzy soft sets, Advances in Fuzzy Systems, Article ID 586507, http://dx.doi.org/10.1155/2009/586507: 1-6.

Aktaş, H. ve Bulut, Ö. (2013). Genelleştirilmiş bulanık esnek cebirsel yapılar, Sakarya Üniversitesi Fen Bilimleri Dergisi, 17(3), 301-306. 
Awasthi, A. ve Kannan, G. (2016). Green supplier development program selection using NGT and VIKOR under fuzzy environment, Computers \& Industrial Engineering, 91, 100-108.

Banaeian, N., Mobli, H., Fahimnia, B., Nielsen, I.E. ve Omid, M. (2018). Green supplier selection using fuzzy group decision making methods: A case study from the agri-food industry, Computer and Operations Research, 89, 337-347.

Bansal, S., Biswas, S. ve Singh, S.K. (2017). Fuzzy decision approach for selection of most suitable construction method of green buildings, International Journal of Sustainable Built Environment, 6, 122-132.

Başkaya, Z. ve Öztürk, B. (2011). Bulanık TOPSIS algoritması ile yamuk bulanık sayıların satış elemanı seçiminde kullanılması, Business and Economics Research Journal, Volume 2(2), 77100.

Borah, M., Neog, T.J. ve Sut, D.K. (2012). A study on some operations of fuzzy soft sets, International Journal of Modern Engineering Research (IJMER), 2(2), 219-225.

Chen-Tung, C., Lin, C.T. ve Huang, S.F. (2006). A fuzzy approach for supplier evaluation and selection in supply chain management, International Journal of Production Economics, 102, 289-301.

Çağman, N., Enginoğlu, S. ve Çıtak, F. (2011). Fuzzy soft set theory and its applications, Iranian Journal of Fuzzy Systems, 8(3), 137-147.

Çelik, Y. (2016). Genelleştirilmiş trapezoidal bulanık esnek kümeler ve karar verme problemlerinde uygulamas1, Karaelmas Fen ve Mühendislik Dergisi, 6 (1), 121-129.

Freeman, J. ve Chen, T. (2015). Green supplier selection using an AHP-Entropy-TOPSIS framework, Supply Chain Management: An International Journal, 20 (3), 327-340.

Govindan, K., Rajendran, S., Sarkis, J. ve Murugesan, P. (2015). Multi criteria decision making approaches for green supplier evaluation and selection: A literature review, Journal of Cleaner Production, 98: 66-83.

Guneri, A.F., Yucel, A. ve Ayyildiz, G. (2009). An integrated fuzzy-lp approach for a supplier selection problem in supply chain management, Expert Systems with Applications, 36, 9223 9228.

Hervani, A.A., Helms, M.M. ve Sarkis, J. (2005). Performance measurement for green supply chain management, Benchmarking: An International Journal, 12(4), 330-353.

Kannan,D., Khodaverdi, R., Olfat, L, Jafarian, A. ve Diabat, A. (2013). Integrated fuzzy multi criteria decision making method and multiobjective programming approach for supplier selection and order allocation in a green supply chain, Journal of Cleaner Production, 47, 355367.

Kong, Z., Gao, L. ve Wang, L. (2009). Comment on a fuzzy soft set theoretic approach to decision making problems', Journal of Computational and Applied Mathematics, 223, 540-542.

Kuo, R.J., Wang, Y.C. ve Tien,F.C. (2010). Integration of artificial neural network and MADA methods for green supplier selection, Journal of Cleaner Production, 18, 1161-1170.

Lu, L.Y.Y., Wu, C.H. ve Kuo, T.C. (2007). Environmental principles applicable to green supplier evaluation by using multi-objective decision analysis, International Journal of Production Research, 45(18-19), 4317-4331.

Maji, P.K., Roy, A.R. ve Biswas, R. (2002). An application of soft sets in a decision making problem, Computers and Mathematics with Applications, 44, 1077-1083.

Majumdar, P. ve Samanta, S.K. (2010). Generalised fuzzy soft sets, Computers and Mathematics with Applications, 59, 1425-1432. 
Molodtsov, D. (1999). Soft set theory- first results, Computers and Mathematics with Applications, 37, 19-31.

Roy, A.R. ve Maji, P.K. (2007). A fuzzy soft set theoretic approach to decision making problems, Jornal of Computational and Applied Mathematics, 203, 412-418.

Şişman, B. (2016). Bulanık MOORA yöntemi kullanılarak yeşil tedarikçi geliştirme programlarının seçimi ve değerlendirilmesi, Journal of Yasar University, 11(44), 302-315.

Taş, N., Özgür Y1lmaz, N. ve Demir, P. (2017). An application of soft set and fuzzy soft set theories to stock management, Süleyman Demirel Üniversitesi Fen Bilimleri Enstitüsü Dergisi, 21(3): 791-796.

Xiao, Z., Xia, S., Gong, K. ve Li, D. (2012). The trapezoidal fuzzy soft set and its application in MCDM", Applied Mathematical Modelling, 36, 5844-5855.

Xie, N., Wen, G. ve Li, Z. (2014). A method for fuzzy soft sets in decision making based on grey relational analysis and D-S theory of evidence: Application to medical diagnosis, Computational and Mathematical Methods in Medicine, 2014: 1-12.

Yao, B.X., Liu, J.L. ve Yan, R.X. (2008). Fuzzy soft set and soft fuzzy set, Fourth International Conference on Natural Computation: 252-255.

Yazdani, M. (2014). An integrated MCDM approach to green supplier selection, International Journal of Industrial Engineering Computations, 5: 443-458.

Zadeh, L.A. (1965). Fuzzy Sets, Information and Control, 8(3): 338-353.

ETIKK ve BİLIMSEL İLKELER SORUMLULUK BEYANI

$\mathrm{Bu}$ çalışmanın tüm hazırlanma süreçlerinde etik kurallara ve bilimsel atıf gösterme ilkelerine riayet edildiğini yazar(lar) beyan eder. Aksi bir durumun tespiti halinde Afyon Kocatepe Üniversitesi Sosyal Bilimler Dergisi'nin hiçbir sorumluluğu olmayıp, tüm sorumluluk makale yazarlarına aittir.

\section{ARAŞTIRMACILARIN MAKALEYE KATKI ORANI BEYANI}

1. yazar katkı oranı: \%100 